\title{
Commentary: When the data are precise and imperfect
}

\author{
Ashish S. Shah, MD
}

Its surprisingly difficult to merge databases. Databases are designed to serve a particular mission and so the architecture, variables, and functionality can be shockingly idiosyncratic. Large administrative databases are monstrous spreadsheets on steroids. Therefore, the notion that one can just mash 2 together to develop meaningful and useful tools is ambitious to say the least. Its exceptionally difficult work, and therefore the current study by the group at the University of Michigan is an extraordinary effort to merge the Society of Thoracic Surgeons/Intermacs database with the massive Medicare database is both important and cautionary. ${ }^{1}$ The authors chose to use this merger to ask questions about a relatively complex phenomena: hospital-level variability and economic impact of left ventricular assist device (LVAD)-related infection. The authors have shown that there is a surprisingly high incidence of LVAD infections across the United States and among individual hospitals. The cost (to the extent that one can estimate this mysterious issue in the United States) also varies. Not surprisingly, more infections cost more money.

Why is this important? First, bringing administrative datasets into the hands of clinicians is critical. We all need to have a working understanding of the data and not just rely on administrators and policy makers to have a monopoly or frankly a mastery of this information. They will make decisions, and clinicians need to be a part of this process. Second, the accurate interpretation of clinical data is complex and demands experts to evaluate the process, data, and conclusions. In the current study, the various infections, while listed, may have different clinical significance. Some

\footnotetext{
From the Department of Cardiac Surgery, Vanderbilt University Medical Center, Vanderbilt Medical Center East, Nashville, Tenn.

Disclosures: The author reported no conflicts of interest.

The Journal policy requires editors and reviewers to disclose conflicts of interest and to decline handling or reviewing manuscripts for which they may have a conflict of interest. The editors and reviewers of this article have no conflicts of interest.

Received for publication May 7, 2021; revisions received May 7, 2021; accepted for publication May 7, 2021; available ahead of print May 15, 2021

Address for reprints: Ashish S. Shah, MD, Department of Cardiac Surgery, Vanderbilt University Medical Center, Vanderbilt Medical Center East, 1215 21st Ave South, Suite 5025, Nashville, TN 37232 (E-mail: ashish.s.shah@vanderbilt.edu).

J Thorac Cardiovasc Surg 2022;164:1569

$0022-5223 / \$ 36.00$

Copyright (C) 2021 by The American Association for Thoracic Surgery

https://doi.org/10.1016/j.jtcvs.2021.05.021
}

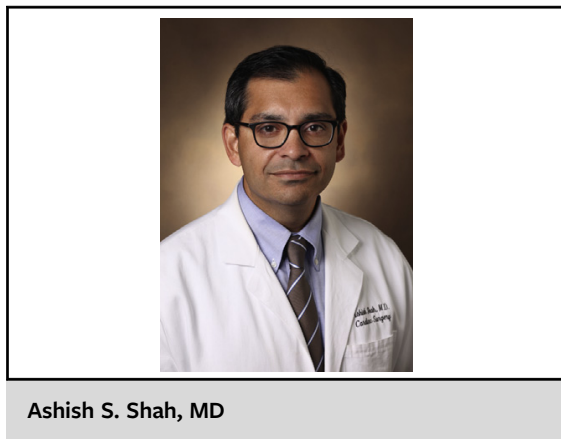

CENTRAL MESSAGE

The current study has integrated

a comprehensive clinical data-

base with a massive financial one.

The results share some inter-

esting truths but also highlight

the limitations of even large

datasets.

driveline infections are inconsequential and the reported protozoan infections likely catastrophic. But that's not available in these datasets. Finally, deciding what to do about it depends on where this particular problem fits in the overall care of the patient with an LVAD. The costs associated are relatively small compared with a year of life of patients with advanced heart disease.

There are number of questions that arise from this important study. Why are infections and costs so variable in the United States? Why haven't best practices infiltrated the LVAD world in a way that should limit variability? Should we derive performance benchmarks that are tied to cost? How do we account for the simple fact that it costs more in New York City to do anything than it does in Nashville or Ann Arbor? Maybe not Nashville.

The current study is ushering in a new chapter in how we use administrative databases. This merger between a true clinical database and a financial one will provide new insights, new tools, and new headaches for clinicians, hospital administrators, and policy directors. Nonetheless, it is necessary and worth it despite all the precise imperfections.

\section{Reference}

1. Likosky DS, Yang G, Zhang M, Malani PN, Fetters MD, Stobel RJ, et al. Interhospital variability in health care-associated infections and payments after durable ventricular assist device implant among Medicare beneficiaries. J Thorac Cardiovasc Surg. 2022;164:1561-8. 